DE

M E D I C I N A

T R O P I C A L

$\mathrm{DE}$

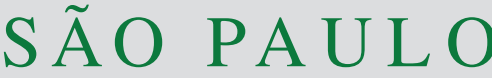

JOURNAL OF THE SÃO PAULO INSTITUTE OF TROPICAL MEDICINE

'Secretaria de Estado da Saúde de São Paulo, Coordenadoria de Controle de Doença, Instituto Adolfo Lutz, Centro de Imunologia, São Paulo, São Paulo, Brazil

Correspondence to: Adele Caterino-deAraujo

Secretaria de Estado da Saúde de São Paulo, Coordenadoria de Controle de Doença, Instituto Adolfo Lutz, Centro de Imunologia, Av. Dr. Arnaldo, 351, $11^{\circ}$ andar, CEP 01246-000, Pacaembu, São Paulo, SP, Brazil

Tel +55 1130682898

E-mail: adele.caterino@ial.sp.gov.br, caterino@alumni.usp.br

Received: 23 January 2020

Accepted: 14 April 2020

\section{Pooling of sera for human T-cell lymphotropic virus (HTLV) screening in a time of increasing health care expenditure and limited resources}

Rafael Xavier da Silva', Karoline Rodrigues Campos ${ }^{1}$, Adele Caterino-de-Araujo ${ }^{1}$

\section{ABSTRACT}

Identifying the true prevalence of human T-cell lymphotropic virus, mostly type 1 (HTLV-1), and the number of patients with HTLV-1-associated diseases, in addition to introducing HTLV-1/2 serology during the prenatal of pregnant women and in individuals infected with other viruses that share transmission routes with HTLV-1, are actions that could help to recognize the importance of this virus by WHO and national health organizations, and to control its transmission/dissemination. As Brazil is endemic to HTLV and there is an increase in health care expenditure, but resources are limited, any strategy that could reduce the cost of HTLV screening is needed and welcomed. This study aimed to determine whether the strategy of pooling sera for HTLV antibody determination is feasible and reduces the costs. Two enzyme immunoassays (EIA Murex HTLV-I+II, Diasorin, UK, and Gold ELISA HTLV-1+2, REM Ind. Com. Ltda., SP, Brazil), and serum samples that resulted in different levels of HTLV-1/2 antibodies by EIA and of which a volume allowed assay validation were employed for analysis. The diagnostic sensitivity and specificity and Cohen's Kappa value, as well as the accuracy and precision were analyzed. After validating the five-sample pool using the EIA Murex (Cohen's Kappa = 1.0), the technique was employed for individual cost comparison in 2,625 serum samples from populations at risk of HTLV infections (HBV, HCV, and HIV-infected individuals). The results from individual and pooled samples confirmed the diagnostic sensitivity $(100 \%)$ and specificity $(100 \%)$ of the pooling and a cost minimization varying from $60.7 \%$ to $73.6 \%$. In conclusion, the results of this study suggest the use of pooling sera in sero-epidemiological surveillance studies and possibly in prenatal care screening programs in Brazil.

KEYWORDS: HTLV-1. HTLV-2. Serology. Screening. Pooling sera. Cost minimization.

\section{INTRODUCTION}

In recent years, several attempts have been made to persuade the World Health Organization (WHO) and other local health organizations to include human T-cell lymphotropic virus, primarily type 1 (HTLV-1) and associated diseases, in the list of neglected pathogens/infectious diseases ${ }^{1-4}$. This is due to the high number of HTLV-infected individuals worldwide ${ }^{1,5}$, as well the high mortality and morbidity of HTLV-1-associated diseases, such as adult T-cell leukemia/lymphoma (ATLL) and HTLV-1-associated myelopathy/tropical spastic paraparesis (HAM/TSP) ${ }^{1-6}$.

Identifying the true prevalence of HTLV-1-infected individuals and the number of patients with HTLV-1-associated diseases is one way to highlight the importance of this neglected human retrovirus ${ }^{1,2,4,6}$. Currently, introducing HTLV-1/2 serology in prenatal care for pregnant women to avoid breastfeeding transmission ${ }^{4,6,7}$, 
in individuals infected with other viruses that share transmission routes with HTLV-1/2 ${ }^{8-10}$, and including HTLV in the National Mandatory Notification List are actions to control HTLV transmission/dissemination in Brazil and worldwide ${ }^{2,4,10}$. As Brazil is endemic to HTLV- $1 / 2^{5}$ and at a time in which there is increasing health care expenditure, but resources are limited, any strategy that could reduce the cost of HTLV screening is needed and welcomed. Indeed, since HTLV-1 and HTLV-2 have different pathogenicity, discriminating HTLV-1 from HTLV-2 is important for a better follow-up of infected individuals ${ }^{11}$.

Several years ago, the strategy based on pooling of samples was shown to be feasible for large-scale seroepidemiological studies in HIV ${ }^{12,13}$, and more recently in $\mathrm{HTLV}^{14,15}$. By using samples from various population groups and enzyme-linked immunosorbent assays (ELISAs) for screening, the strategy saves resources in terms of labor and test reagents ${ }^{12-15}$.

Although there are several methods for the health economic evaluation that consider both, cost and consequences, such as cost minimization, cost effectiveness, cost utility, cost benefit, and other economic modeling, cost minimization seems to be appropriate for comparing individual samples and pooled samples in screening when it is assumed that the final result is the same ${ }^{16}$.

Based on the above mentioned information and the fact that the pooling of serum samples has not been employed for HTLV screening in Brazil, we decided to conduct the present study, to ascertain the feasibility of this strategy for detecting antibodies to HTLV-1, HTLV-2 and HTLV untypeable truly positive samples in populations at risk.

\section{MATERIALS AND METHODS}

\section{Samples and assays}

Firstly, 81 serum samples from a biorepository that resulted in HTLV-1-, HTLV-2- or HTLV-positive but untypeable serological assays were reanalyzed by two enzyme immunoassays (EIAs) commonly used for screening in public health laboratories in Brazil (EIA Murex HTLV-I+II, Diasorin, UK, and Gold ELISA HTLV-1+2, REM Ind. Com. Ltda., SP, Brazil), and the reactions and interpretation of results were conducted according to the respective manufacturers' instructions. Briefly, these assays are sandwich enzyme immune assays with recombinant antigens and synthetic peptides capable of detecting all the classes of HTLV-1- and HTLV-2-specific antibodies. The optical density-to-cut off ratio (OD/CO) was determined and considered reactive when OD/CO was $>1.0$. Samples with $1.1 \leq \mathrm{OD} / \mathrm{CO} \geq 0.9$ were considered borderline or in the gray zone $(10 \% \pm \mathrm{CO})$ for HTLV-1/2 antibodies. Notably, samples considered reactive and borderline on screening were tested by Western blot (WB, HTLV BLOT 2.4, MP Biomedicals Asia Pacific Pte Ltd., Genelabs) and line immunoassay (LIA, INNO-LIA HTLV-I/II Score, Fujirebio, Europe N. V, Belgium) for confirming HTLV positivity. The reactions and criteria for interpretation of the serological confirmatory results (bands) were made according to the manufacturers' instructions and are described in detail elsewhere ${ }^{17}$

Samples that presented the lowest reactivity and highest reactivity results in both EIA screening assays, of which the volume was sufficient for testing and validating the pooling strategy, were employed for analysis.

Initially, to ascertain the feasibility of the use of the pooling in screening, five serum samples, two HTLV-1 (one of low and one of high OD/CO value), two HTLV-2 (one of low and one of high OD/CO value), and one HTLV (high OD/CO value), were diluted in two steps; firstly, in serum from a negative blood bag for infectious blood-borne diseases using serial dilution starting in 1/2, 1/4, 1/8, 1/16, $1 / 32,1 / 64$ and interposing the dilution $1 / 5,1 / 10$ and $1 / 20$; samples that continued HTLV reactive at 1/64 were diluted until the end point titration. Subsequently, after knowing the highest serum dilution without loss of reactivity in both EIAs and deciding which one was more suitable to be used in the pool, the samples were diluted in different positive and negative HIV, HBV and HCV serum samples to ensure that these infectious agents would not interfere in the pooling strategy.

Afterwards, samples containing sufficient volume for the diagnostic method validation assays were selected and tested for the pooling strategy using the guideline established by the Instituto Adolfo Lutz (P-SG-0022 Validação de métodos de ensaio de diagnóstico), which agrees with a protocol described in the literature ${ }^{18}$. Forty pools were employed for accuracy analysis (35 containing serum samples from HTLV-1, HTLV-2 or HTLV seropositive patients, and five containing samples from healthy control individuals, negative for HTLV-1/2), tested only once and for five consecutive days, along with up to seven pools for the precision analysis (five containing serum samples from HTLV-1, HTLV-2 or HTLV-positive patients, and two from negative controls). The intra-assay (repeatability) of the pooling was conducted in triplicate over five consecutive days, and the inter-assay (reproducibility) in duplicate performed by three analysts. Of note, all the pools were prepared at the same time, divided into aliquots, and stored at $4{ }^{\circ} \mathrm{C}$ (refrigerator) until use (maximum five days). Figure 1 presents the flowchart of the steps and the samples employed in the study. 
Finally, for calculating the diagnostic sensitivity and specificity and the cost minimization of the HTLV-1/2 screening using individual samples and pooled samples, 2,000 serum/plasma samples from patients with viral hepatitis B and C and 625 plasma samples from patients with HIV/AIDS that had been individually screened using the same EIA, of which the results had been published elsewhere ${ }^{19,20}$, were employed. The cost minimization in percentage was calculated considering the value in
American dollars (U\$ 1.5 per reaction) in the EIA acquired in 2019.

\section{Statistical analysis}

The laboratory results were recorded and analyzed using Epi Info version 3.5.4 software (CDC, Atlanta, GA, USA). For validation, the accuracy of the pooling assay was assured by determining the diagnostic sensitivity and

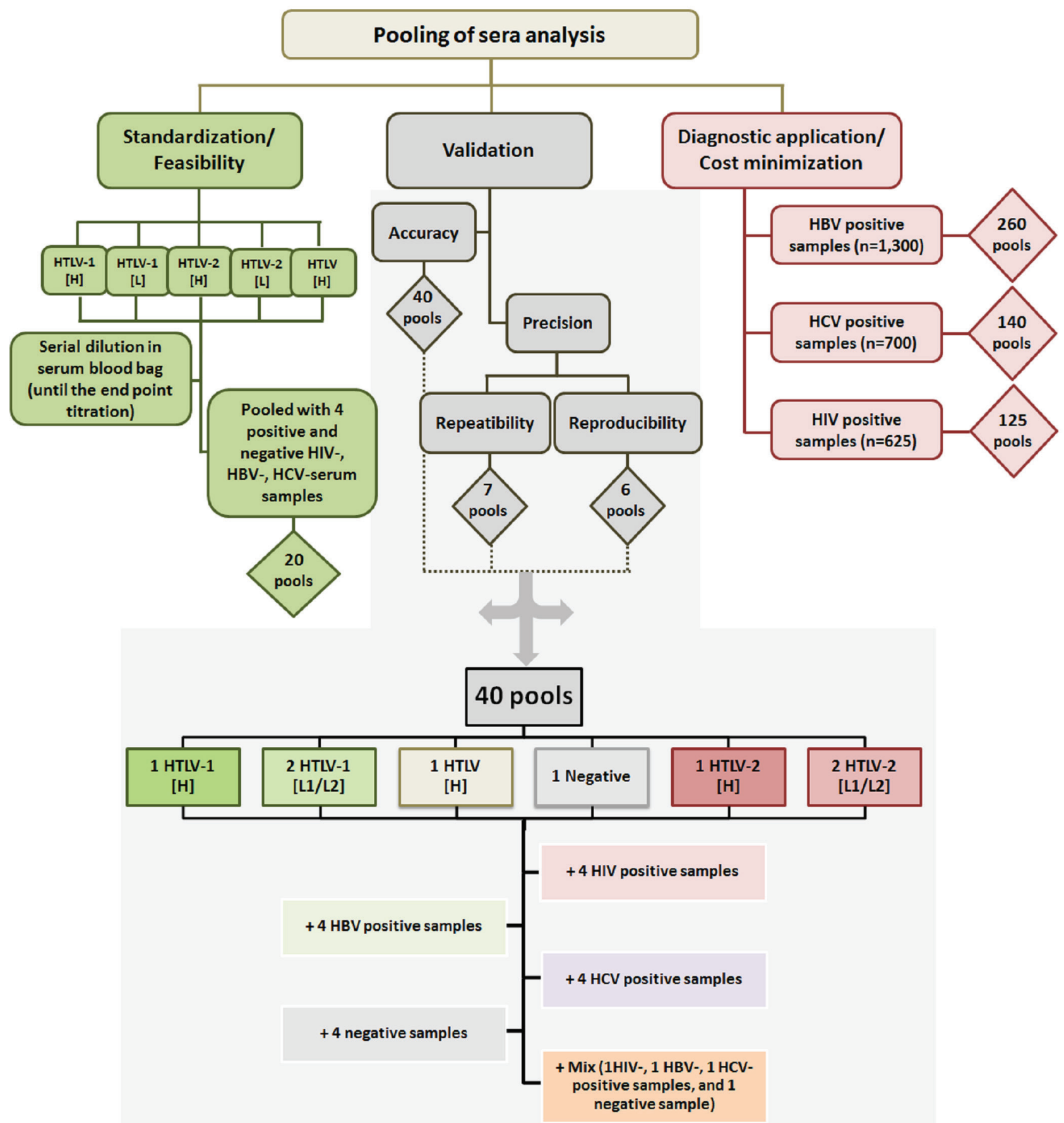

Figure 1 - Flowchart of the steps and the samples employed in the human T-cell lymphotropic virus (HTLV) screening, using the pooling of sera strategy. $\mathrm{H}=$ high reactive sample by $\mathrm{EIA} ; \mathrm{L}=$ low reactive sample by $\mathrm{EIA}$. 
specificity and Cohen's Kappa value. GraphPad Prism version 5.00 [Trial] software (GraphPad Software, San Diego, CA, USA), was employed for precision analysis (repeatability and reproducibility) by calculating the mean $\mathrm{OD} / \mathrm{CO}$ value, standard deviation (SD), and coefficient of variation in percentage $(\mathrm{CV})$. The total values of mean, $\mathrm{SD}$ and $\mathrm{CV}$ were calculated considering the values obtained in each reaction.

\section{RESULTS}

Table 1 presents the results of $\mathrm{OD} / \mathrm{CO}$ obtained in serum samples with low and high HTLV-1/2 antibody titers when individually analyzed by Murex and Gold ELISA and after serial dilution in normal HTLV-negative plasma. They disclosed that the highest serum dilutions without loss of reactivity in samples with low $\mathrm{OD} / \mathrm{CO}$ results were $1 / 5$ (Murex) and 1/2 (Gold ELISA), independent of HTLV-1 or HTLV-2 infection (Table 1, in bold).

After establishing the highest dilution (1/5) without loss of reactivity for any type of sample (HTLV-1, HTLV-2 or HTLV low or high positives) and the better EIA for use in the pool (Murex), the lack of interference or cross-reactivity of the pooling assays was confirmed using plasma samples of different infected individuals (HIV, HBV and HCV) and negative controls (Table 2).
When 40 pools of sera were tested, the accuracy of the pooling was confirmed, although on day five, one pool containing one HTLV-1 low reactive serum sample resulted in a borderline result in the EIA (Figure 2).

Briefly, the repeatability of the pooling was confirmed disclosing coefficient of variations (CV) ranging from $6.46 \%$ to $16.13 \%$. The pool that presented the highest CV was the one containing an HTLV-2 low reactive sample (Table 3).

Concisely, the reproducibility of the pooling assay by three analysts was $100 \%$; generating no false-positive or false-negative result. The total $\mathrm{CV}$ values in pools containing HTLV-1-, HTLV-2- and HTLV-positive serum samples ranged from $4.74 \%$ to $8.37 \%$, and the highest CV (17.70\%) was detected in a pool containing only HTLV-negative samples (Table 4).

After validating the five-sample pool using EIA Murex, the technique was employed for individual cost comparison in 2,625 serum samples previously screened, of which the final HTLV confirmatory results were published elsewhere: 1,300 from patients with hepatitis $\mathrm{B}, 700$ with hepatitis C, and 625 with HIV/AIDS ${ }^{19,20}$. The results from individual and pooled samples confirmed the diagnostic sensitivity $(100 \%)$ and specificity $(100 \%)$ of the pooling (Cohen's Kappa $=1.0$ ), and a cost minimization of $70.4 \%, 60.7 \%$ and $73.6 \%$ in these populations (Figure 3), depending on

Table 1 - Major serum dilution capable of detecting HTLV-1/2 truly positive samples using two enzyme immunoassays.

\begin{tabular}{lcccccc}
\hline \multirow{2}{*}{ Sample } & Murex & Gold ELISA & \multicolumn{3}{c}{ Murex } & \multicolumn{2}{c}{ Gold ELISA } \\
\cline { 2 - 7 } & OD/CO & OD/CO & Dilution* & OD/CO & Dilution* $^{*}$ OD/CO \\
\hline HTLV-1 (H) & 13.35 & $>9.6$ & $1 / 65,536$ & 1.59 & $1 / 8,192$ & 1.93 \\
HTLV-1 (L) & 6.7 & 3.7 & $1 / 5$ & 1.14 & $1 / 4$ & 1.89 \\
HTLV-2 (H) & 13.41 & 9.6 & $1 / 16,384$ & 1.04 & $1 / 2,048$ & 1.06 \\
HTLV-2 (L) & 7.15 & 2.1 & $1 / 10$ & 1.02 & $1 / 2$ & 1.03 \\
HTLV (H) & 12.94 & 8.6 & $1 / 128$ & 1.77 & $1 / 32$ & 1.81 \\
\hline
\end{tabular}

Murex and Gold ELISA assays according to the manufacturer's instructions; *Serum sample dilution in blood donor bags negative for all blood-borne infectious agents; $\mathrm{OD} / \mathrm{CO}=$ optical density-to-cut off ratio; $\mathrm{H}=$ high reactive sample by $E I A ; \mathrm{L}=$ low reactive sample by EIA. In bold, the highest serum dilutions without loss of reactivity in low reactive samples.

Table 2 - HTLV-1/2 optical density-to-cut off values of high and low reactive serum samples when pooled in samples from individuals infected and uninfected with HIV, HBV and HCV using EIA Murex.

\begin{tabular}{lccccc}
\hline Sample & Individual sample & $\mathrm{HIV}^{*}$ & $\mathrm{HBV}^{*}$ & $\mathrm{HCV}^{*}$ & Negative $^{* *}$ \\
\hline HTLV-1 (H) & 13.35 & 13.08 & 13.11 & 13.22 & 13.11 \\
HTLV-1 (L) & 6.7 & 1.48 & 1.53 & 2.09 & 1.86 \\
HTLV-2 (H) & 13.41 & 13.05 & 13.02 & 13.24 & 13.21 \\
HTLV-2 (L) & 7.15 & 2.43 & 2.13 & 2.83 & 2.21 \\
HTLV (H) & 12.94 & 12.46 & 11.8 & 12.45 & 11.33 \\
\hline
\end{tabular}

$\mathrm{H}=$ high reactive samples by Murex; $\mathrm{L}=$ low reactive sample by Murex; ${ }^{*}$ pool of five sera samples (one infected with $\mathrm{HTLV}$ and four infected with HIV or HBV or HCV); ** pool of five sera samples (one infected with HTLV and four uninfected with HIV, HBV and HCV). 


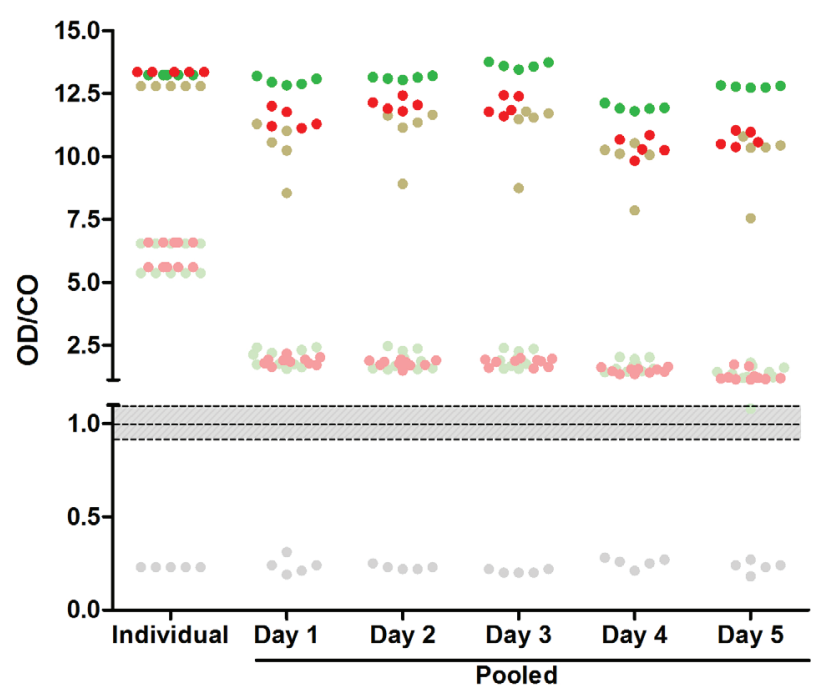

Figure 2 - Accuracy of the pooling strategy: comparison of the optical density-to-cut off (OD/CO) values obtained in 40 pools containing sera which were tested individually and in pools, and that ascertain the feasibility of the pooling strategy in HTLV-1/2 antibody screening using EIA Murex. Light green dots = pools of sera containing samples with low levels of HTLV-1 antibodies; dark green dots $=$ pools of sera containing samples with high levels of HTLV-1 antibodies; light red dots = pools of sera containing samples with low levels of HTLV-2 antibodies; dark red dots $=$ pools of sera containing samples with high levels of HTLV-2 antibodies; light brown dots = pools of sera containing samples with high levels of HTLV antibodies; gray dots = pools of sera containing samples negative for HTLV antibodies. $\mathrm{H}=$ high reactive sample by EIA; $\mathrm{L}=$ low reactive sample by EIA. Composition of pools according to Materials and Methods.

the prevalence of HTLV-1/2 (1.9\% in HBV, $4.0 \%$ in HCV, and $1.1 \%$ in patients with HIV/AIDS) ${ }^{19,20}$.

Briefly, the 1,330 HBV positive serum samples were grouped into 260 pools; HTLV-1/2 screening disclosed 25 HTLV-positive pools. When the sera that composed these 25 pools were analyzed separately $(n=125)$, one pool had two positive samples; the same 26 samples were detected in individual analysis ${ }^{20}$. A cost minimization of $70.4 \%$ would have been achieved if this strategy had been employed (total of 385 reactions instead of 1,330 reactions, Figure 3A). The same calculation was employed in HCV: the $700 \mathrm{HCV}$ positive serum samples were grouped in 140 pools; 27 were positive by EIA, and when the sera that formed the 27 positive pools were analyzed individually, two pools presented two positive samples; the same samples were detected in previous individual analysis ${ }^{20}$. For calculating the cost minimization, 140 reactions tested in pool plus 135 tested individually, totaling 275 reactions instead of 700 reactions, with a cost minimization of $60.7 \%$ (Figure 3B). Finally, the 625 positive serum samples of HIV/AIDS were grouped into 125 pools; eight were EIA positive; therefore, 125 reactions plus 40 reactions, total of 165 reactions instead of 625 reactions, with a cost minimization of $73.6 \%$ (Figure 3C). Of note, in HIV/AIDS, one of the eight reactive pools was capable of detecting a borderline $\mathrm{OD} / \mathrm{CO}$ sample identified previously in individual analysis, and this sample did not confirm HTLV-1/2 infection by Western Blot and INNO-LIA ${ }^{19}$.

\section{DISCUSSION}

In recent years, several attempts have been made to make HTLV-1 infection and associated diseases visible worldwide and in Brazil ${ }^{1-4}$. One of the means to achieve this goal is to know the real prevalence of the infection and associated diseases in the general population and in individuals who could acquire/transmit this infection more easily, such as individuals infected with other microorganisms that share routes of transmission with HTLV-1 ${ }^{8,9,19,20}$ and HTLV-1-infected mothers who could transmit the virus to their infants during breastfeeding ${ }^{4,6,7}$. In Brazil, the estimated number of HTLV-1-infected

Table 3 - Intra-assay results (repeatability) of HTLV-1/2 antibody determination in triplicate over five consecutive days using EIA Murex and pool of five serum samples with different compositions.

\begin{tabular}{|c|c|c|c|c|c|c|c|c|c|c|c|c|c|c|c|c|c|c|c|c|}
\hline \multirow{2}{*}{ ID Pool } & \multirow{2}{*}{ Sample } & \multicolumn{19}{|c|}{$\mathrm{OD} / \mathrm{CO}$} \\
\hline & & Individual & Mean $_{D 1}$ & $\mathrm{SD}_{\mathrm{D} 1}$ & $\mathrm{CV}_{\mathrm{D} 1} \%$ & Mean $_{\mathrm{D} 2}$ & $\mathrm{SD}_{\mathrm{D} 2}$ & $\mathrm{CV}_{\mathrm{D} 2} \%$ & Mean $_{\mathrm{D} 3}$ & $\mathrm{SD}_{\mathrm{D} 3}$ & $\mathrm{CV}_{\mathrm{D} 3} \%$ & Mean $_{\mathrm{D} 4}$ & $\mathrm{SD}_{\mathrm{D} 4}$ & $\mathrm{CV}_{\mathrm{D} 4} \%$ & Mean $_{\mathrm{D} 5}$ & $\mathrm{SD}_{\mathrm{D} 5}$ & $\mathrm{CV}_{\mathrm{D} 5} \%$ & Mean $_{\mathrm{T}}$ & $\mathrm{SD}_{\mathrm{T}}$ & $\mathrm{CV}_{\mathrm{T}} \%$ \\
\hline$P-09^{a}$ & HTLV-1 [L1] & 5.36 & 1.36 & 0.05 & 3.95 & 1.54 & 0.05 & 3.01 & 1.40 & 0.08 & 5.93 & 1.38 & 0.09 & 6.36 & 1.19 & 0.08 & 6.60 & 1.37 & 0.13 & 9.55 \\
\hline$P-14^{a}$ & HTLV-1 [L2] & 6.54 & 1.76 & 0.09 & 5.32 & 1.89 & 0.06 & 3.30 & 1.73 & 0.06 & 3.19 & 1.72 & 0.04 & 2.26 & 1.58 & 0.03 & 1.60 & 1.74 & 0.12 & 6.70 \\
\hline$P-19^{a}$ & HTLV & 12.79 & 11.93 & 0.24 & 2.01 & 10.83 & 0.17 & 1.61 & 10.26 & 0.04 & 0.42 & 10.41 & 0.04 & 0.53 & 10.12 & 0.11 & 1.12 & 10.71 & 0.69 & 6.46 \\
\hline$P-24^{a}$ & Negative & 0.23 & 0.22 & 0.01 & 3.64 & 0.23 & 0.03 & 13.08 & 0.23 & 0.03 & 14.87 & 0.26 & 0.03 & 10.69 & 0.26 & 0.01 & 5.48 & 0.24 & 0.03 & 11.44 \\
\hline$P-25^{b}$ & Negative & 0.23 & 0.23 & 0.03 & 12.28 & 0.21 & 0.02 & 7.39 & 0.23 & 0.04 & 16.06 & 0.22 & 0.01 & 3.83 & 0.21 & 0.01 & 2.65 & 0.22 & 0.02 & 9.51 \\
\hline $\mathrm{P}-34^{\mathrm{a}}$ & HTLV-2 [L1] & 6.58 & 1.57 & 0.02 & 1.25 & 1.50 & 0.16 & 10.47 & 1.54 & 0.03 & 1.65 & 1.43 & 0.04 & 3.13 & 1.25 & 0.01 & 0.99 & 1.46 & 0.13 & 9.22 \\
\hline P-39a & HTLV-2 [L2] & 5.6 & 1.71 & 0.09 & 5.23 & 1.61 & 0.06 & 3.49 & 1.81 & 0.17 & 9.42 & 1.52 & 0.21 & 14.01 & 1.17 & 0.05 & 4.42 & 1.56 & 0.25 & 16.13 \\
\hline
\end{tabular}


Table 4 - Inter-assay results (reproducibility) of HTLV-1/2 antibody determination in duplicate performed by three analysts using EIA Murex and pool of five serum samples with different compositions.

\begin{tabular}{|c|c|c|c|c|c|c|c|c|c|c|c|c|c|c|}
\hline \multirow{2}{*}{$\begin{array}{l}\text { ID } \\
\text { Pool }\end{array}$} & \multirow{2}{*}{ Sample } & \multicolumn{13}{|c|}{$\mathrm{OD} / \mathrm{CO}$} \\
\hline & & Individual & Mean $_{\mathrm{A} 1}$ & $\mathrm{SD}_{\mathrm{A} 1}$ & $\mathrm{CV}_{\mathrm{A} 1} \%$ & Mean $_{\mathrm{A} 2}$ & $\mathrm{SD}_{\mathrm{A} 2}$ & $\mathrm{CV}_{\mathrm{A} 2} \%$ & Mean $_{\mathrm{A} 3}$ & $\mathrm{SD}_{\mathrm{A} 3}$ & $\mathrm{CV}_{\mathrm{A} 3} \%$ & Mean $_{\mathrm{T}}$ & $\mathrm{SD}_{\mathrm{T}}$ & $\mathrm{CV}_{\mathrm{T}} \%$ \\
\hline$-09^{a}$ & HTLV-1 [L1] & 5.36 & 1.30 & 0.03 & 2.18 & 1.55 & 0.04 & 2.29 & 1.36 & 0.02 & 1.57 & 1.40 & 0.12 & 8.37 \\
\hline$-14^{a}$ & HTLV-1 [L2] & 6.54 & 1.42 & 0.04 & 2.50 & 1.58 & 0.01 & 0.45 & 1.41 & 0.08 & 6.02 & 1.47 & 0.09 & 6.38 \\
\hline$-19^{a}$ & HTLV & 12.79 & 11.14 & 0.05 & 0.44 & 11.41 & 0.13 & 1.12 & 10.31 & 0.14 & 1.37 & 10.95 & 0.52 & 4,74 \\
\hline $\mathrm{P}-25^{\mathrm{b}}$ & Negative & 0.23 & 0.20 & 0.00 & 0.00 & 0.25 & 0.02 & 8.66 & 0.30 & 0.01 & 2.4 & 0.25 & 0.04 & 17.70 \\
\hline $34^{a}$ & HTLV-2 [L1] & 6.58 & 2.54 & 0.01 & 0.56 & 2.80 & 0.01 & 0.51 & 2.51 & 0.10 & 3.94 & 2.62 & 0.15 & 5.72 \\
\hline$P-39^{a}$ & HTLV-2 [L2] & 5.6 & 1.32 & 0.08 & 5.91 & 1.51 & 0.04 & 2.35 & 1.38 & 0.01 & 0.51 & 1.40 & 0.09 & 6.79 \\
\hline
\end{tabular}

$\mathrm{ID}=$ Pool sera identification; $\mathrm{OD} / \mathrm{CO}=$ optical density-to-cutoff ratio; $\mathrm{SD}=$ standard deviation; $\mathrm{CV}=$ coefficient of variation; $\mathrm{L}=$ low reagent sample by Murex; $\mathrm{A} 1=$ results of analyst $1 ;_{\mathrm{A} 2}=$ results of analyst $2 ;_{\mathrm{A} 3}=$ results of analyst $3 ;_{\mathrm{T}}=$ total results. Pool composition, afour samples $\mathrm{HIV} / \mathrm{HBV} / \mathrm{HCV} /$ HTLV-seronegative, ${ }^{b}$ mix of one HIV-, one HBV-, and one HCV-positive samples plus one HIV/HBV/HCV/HTLV-negative sample. GraphPad Prism version 5.00 [Trial] software (GraphPad Software, San Diego, CA, USA) was employed by calculating the mean OD/CO, SD, and CV values.

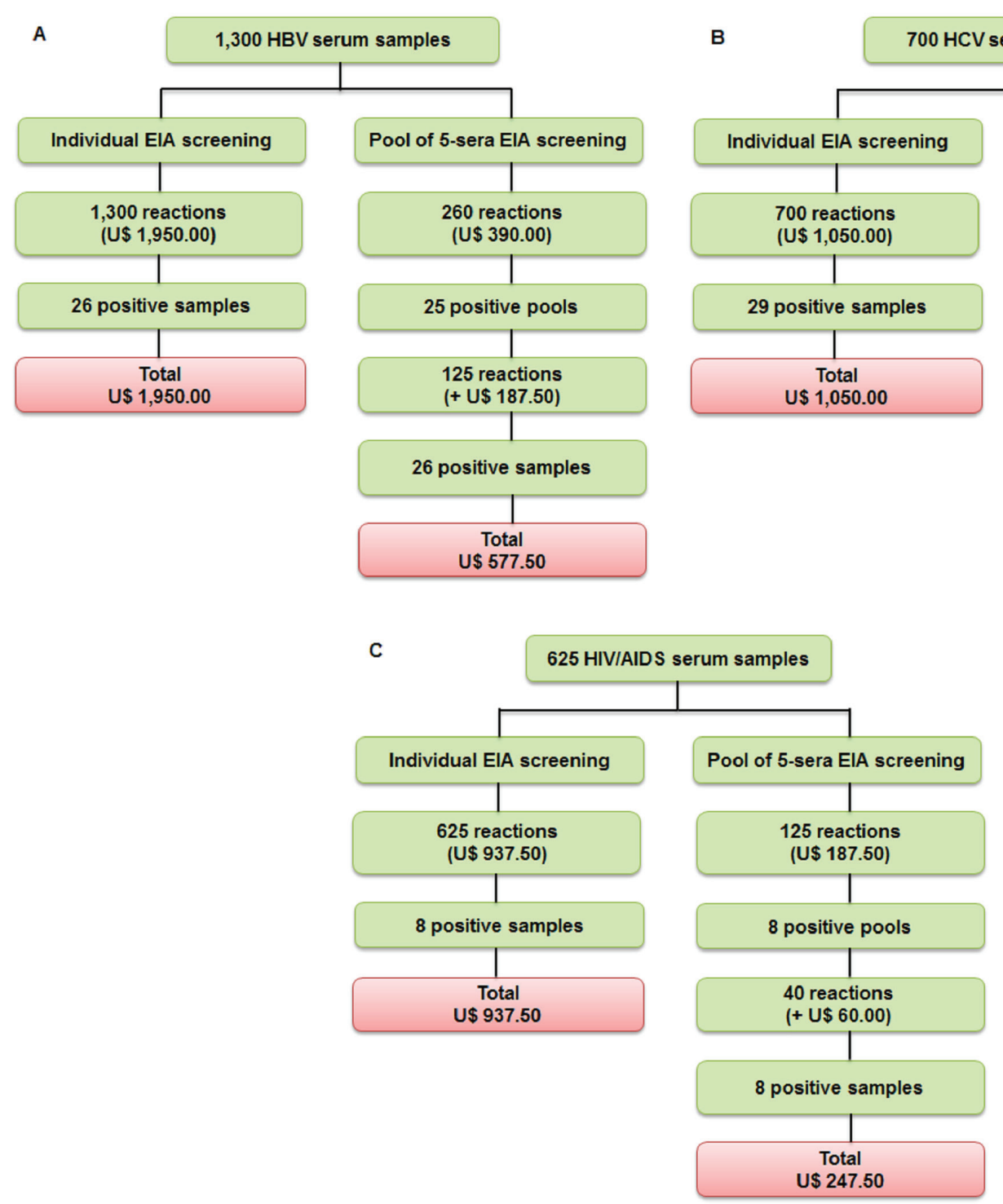

Figure 3 - Costs of HTLV-1/2 antibody screening when conducted in individual serum samples and pool of five serum samples in American dollars (U\$) in populations at risk in Brazil, using EIA Murex. EIA = enzyme immunoassay. 
individuals, as well as individuals with HTLV-1-associated

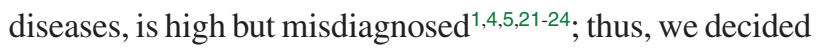
to search for strategies that could reduce the cost of HTLV screening in this country to help the Ministry of Health of Brazil to introduce the serology of HTLV-1/2 in health care programs, especially in the national HTLV antenatal screening program. Using two EIAs commonly employed in screening in public health laboratories in Brazil, we tested the strategy of pooling sera, taking into account previous studies that demonstrated that pooling is feasible and costeffective mostly in populations with low prevalence of HIV and HTLV and/or in countries with limited resources ${ }^{12-15}$.

Both, EIA Murex and Gold ELISA were selected for analysis since their performances were recently well studied in two populations from different regions in Brazil. One study conducted in Sao Paulo (Southeast region) in 127 HIV/Aids individuals pointed to the best performance of the Murex in relation to Gold ELISA. Murex detected higher titers (OD/CO values) of HTLV-1 and HTLV-2 antibodies when compared to Gold ELISA and showed more ability in detecting HTLV truly positive blood samples that were OD/CO non-reactive or borderline in Gold ELISA screening: two HTLV-2 and one HTLV untypeable samples confirmed by Western Blot and/or INNO-LIA and/or Polymerase Chain Reaction (PCR) assays ${ }^{25}$.

The other study conducted in individuals from blood banks seen at the HTLV outpatient clinic in Salvador (Northeastern Brazil) compared the performance of four screening assays: three EIA (including Murex and Gold ELISA) and one chemiluminescence assay (CMIA). Considering truly HTLV-positive $(n=170)$ and HTLV-negative ( $\mathrm{n}=200)$ samples by WB analysis, the best performance among assays was detected with Gold ELISA (100\% sensitivity and $>99.5 \%$ specificity) versus $100 \%$ sensitivity and $92.0 \%$ specificity (Murex) ${ }^{26}$. However, in the same study, when 27 blood samples were analyzed that yielded WB indeterminate results but confirmed HTLV-1 infection by PCR, Murex showed more specificity and accuracy than Gold ELISA ${ }^{26}$. Indeed, when comparing the OD/CO values between the Murex and Gold ELISA, again the Murex presented the higher OD/CO values, which agrees with its use in pooling analysis. Thus, considering these recent studies and the results obtained previously by other groups outside Brazil with pooled samples ${ }^{14,15}$, the EIA Murex was chosen for use in the pool analysis. Serum samples from patients with HIV, HBV or HCV chosen to form the pools were employed to mimic these viruses coinfections that could occur in vivo and to ensure the lack of cross-reactivity of the pooling strategy. Of note, none of the samples truly HTLV-positive was lost using the pool of sera. The unique pool that was borderline on screening was stored for five days and was composed of a low HTLV-1 reactive sample. In any way, this sample was not missed because all the reactive and/or borderline (gray zone) samples would follow to the subsequent steps, which means, individual analyses and confirmatory assays.

Since there is no universal guideline on the optimal way to perform validation/verification experiments of a new technique before being employed in the diagnostic laboratory, we used the guidelines established by the Instituto Adolfo Lutz, which employed qualitative and semi-quantitative analyses and the one that agrees with the guideline established for the clinical virology laboratory described elsewhere, which included explanation of statistical analysis and acceptance/rejection criteria ${ }^{18}$. For the precision analysis, we used the $\mathrm{CV}$ of less than $35 \%$ for acceptance ${ }^{18}$, although the results of $\mathrm{CV}$ obtained with the pooling of five samples and EIA Murex were much smaller than this value and were close to the values described in the manufacturer instructions of the EIA Murex HTLV-I+II, Diasorin, UK, CE-labeled (European Conformity) for single sample analysis (precision intra-assay $\mathrm{CV}$ varying from $4.3 \%$ to $9.3 \%$, and inter-assay from $5.6 \%$ to $11.9 \%$ ). Notably, the results of CV intra- and inter-assays obtained in the present study ranged from $6.46 \%$ to $16.13 \%$ and $4.74 \%$ to $17.70 \%$, respectively.

After validating the pooling strategy, to confirm the diagnostic sensitivity and specificity and cost minimization, the technique was employed in serum samples from HBV, $\mathrm{HCV}$ and HIV/AIDS patients previously tested individually for HTLV-1/2 antibodies ${ }^{19,20}$. The results obtained have confirmed the feasibility and reliability of the assay in sero-epidemiological surveys (Cohen's Kappa $=1$ ) and cost minimizations varying from $60.7 \%$ and $73.6 \%$, depending on the HTLV-1/2 prevalence. The cost reduction was inversely proportional to the prevalence.

Although the present pooling technique was not tested in samples from pregnant women in Brazil, a recent study conducted in the United Kingdom (UK) using paired samples from 21 HTLV-1-infected women taken during pregnancy and while women were not pregnant showed that pregnancy does not impair the diagnosis of HTLV-1/2 by either immunological (CMIA) or molecular (qPCR/ nPCR) tests ${ }^{27}$. Thus, we could suppose that the present pool of five sera using EIA Murex could also be employed in this population. Indeed, this strategy could be helpful for extending the HTLV diagnosis, since: (i) the number of HAM/TSP and ATL cases due to HTLV-1 mother-to-child transmission in Brazil has been underestimated ${ }^{21,22}$, (ii) the low number of HAM/TSP and ATLL cases described in this country could be due to the lack of or misdiagnosis rather than to the low incidence, (iii) the complexity of clinical 
manifestation and laboratory diagnosis of both diseases, (iv) the lack of knowledge in HTLV-1 and associated diseases among health professionals, (v) the difficult access to public health care in Brazil, especially in low-income areas, and (vi) the high morbidity/mortality of diseases ${ }^{21-24}$.

Of note, since 2002, pooling of sera has been employed in blood bank screening programs in the UK; they considered that pooling samples into a single sample reduces serological testing costs; therefore, fewer tests are required, initial and repeatedly reactive samples are reduced since the pooling dilutes low-level reactive samples (false-positive) and requires fewer confirmatory assays ${ }^{28}$. In December 2017, the UK National Screening Committee did not recommend the HTLV-1 testing in the antenatal screening program, but a recent study of the cost effectiveness conducted in the UK showed that screening of pooled samples in pregnant women is cost-effective in all analyzed scenarios ${ }^{29}$.

In conclusion, although the present study has limitations concerning the fact that only one EIA (Murex) was validated and no tests in pregnant women were conducted, the results obtained allow us to suggest the pooling strategy for the HTLV-1/2 national screening programs in Brazil. We recommend local laboratory analyses and validation using currently available commercial tests for HTLV-1/2 screening, pointing out that if CMIA will be employed, probably more samples could be pooled, reducing even more the cost, since the signal-to-cut off $(\mathrm{S} / \mathrm{CO})$ values of this assay are higher than the OD/CO values of EIA, as previously described ${ }^{26}$.

\section{ACKNOWLEDGMENTS}

This study was supported by CAPES (scholarship to RXS and KRC, grant \# 001), FAPESP (grants 2016/03654-0), CCD-SES/SP, and IAL.

\section{AUTHORS' CONTRIBUTIONS}

ACA contributed to the study conception and design; RXS and KRC performed the laboratory experiments; RXS, KRC, and ACA analyzed the data; ACA wrote the manuscript. All the authors have read the paper and approved the final version. RXS, KRC contributed equally to this study.

\section{CONFLICT OF INTERESTS}

The authors declare that they have no conflict of interests.

\section{REFERENCES}

1. Willems L, Hasegawa H, Accolla R, Bangham C, Bazarbachi A, Bertazzoni U, et al. Reducing the global burden of HTLV-1 infection: an agenda for research and action. Antiviral Res. 2017; 137:41-8.

2. Martin F, Tagaya Y, Gallo R. Time to eradicate HTLV-1: an open letter to WHO. Lancet. 2018;391:1893-4.

3. Tagaya Y, Matsuoka M, Gallo R. 40 years of the human T-cell leukemia virus: past, present, and future. F1000Res. 2019;8:F1000 Faculty Rev-228.

4. Puccioni-Sohler M, Grassi MF, Galvão-Castro B, Caterino A, Proietti AB, Vicente AC, et al. Increasing awareness of human T-lymphotropic virus type-1 infection: a serious, invisible, and neglected health problem in Brazil. Rev Soc Bras Med Trop. 2019;52:e20190343.

5. Gessain A, Cassar O. Epidemiological aspects and world distribution of HTLV-1 infection. Front Microbiol. 2012;3:388.

6. Rosadas C, Taylor GP. Mother-to-child HTLV-1 transmission: unmet research needs. Front Microbiol. 2019;10:999.

7. Paiva AM, Assone T, Haziot ME, Smid J, Fonseca LA, Luiz OC, et al. Risk factors associated with HTLV-1 vertical transmission in Brazil: longer breastfeeding, higher maternal proviral load and previous HTLV-1-infected offspring. Sci Rep. 2018;8:7742.

8. Paiva A, Casseb J. Sexual transmission of human T-cell Lymphotropic virus type 1 . Rev Soc Bras Med Trop. 2014;47:265-74.

9. Caterino-de-Araujo A, Alves FA, Campos KR, Lemos MF, Moreira CR. Making the invisible visible: searching for human T-cell lymphotropic virus types 1 and 2 (HTLV-1 and HTLV-2) in Brazilian patients with viral hepatitis B and C. Mem Inst Oswaldo Cruz. 2018;113:130-4.

10. Campos KR, Alves FA, Lemos MF, Moreira RC, Caterino-deAraujo A. The reasons to include the serology of human T-lymphotropic virus types 1 and 2 (HTLV-1 and HTLV-2) in the clinical follow-up of patients with viral hepatitis B and C in Brazil. Plos Negl Trop Dis. In Press 2020.

11. Beilke MA. Retroviral coinfections: HIV and HTLV: taking stock of more than a quarter century of research. AIDS Res Hum Retroviruses. 2012; 28:139-47.

12. Emmanuel JC, Bassett MT, Smith HJ, Jacobs JA. Pooling of sera for human immunodeficiency virus (HIV) testing: an economical method for use in developing countries. J Clin Pathol. 1988;41:582-5.

13. Cahoon-Young B, Chandler A, Livermore T, Gaudino J, Benjamin R. Sensitivity and specificity of pooled versus individual sera in a human immunodeficiency virus antibody prevalence study. J Clin Microbiol. 1989;27:1893-5.

14. Andersson S, Gessain A, Taylor GP. Pooling of samples for seroepidemiological surveillance of human T-cell lymphotropic virus types I and II. Virus Res. 2001;78:101-6.

15. Chang CS, Wu YW, Pan YC, Chen ZY, Wang CS. Feasibility of human T-lymphotropic virus type I screening using pooled 
sera. J Formos Med Assoc. 2002;101:775-8.

16. Rudmik L, Drummond M. Health economic evaluation: important principles and methodology. Laryngoscope. 2013;123:1341-7.

17. Campos KR, Santos FL, Silva Brito V, Gonçalves NL, Araujo TH, Galvão-Castro B, et al. Line Immunoassay for confirmation and discrimination of human T-cell lymphotropic virus infections in inconclusive western blot serum samples from Brazil. J Clin Microbiol. 2019;58:e01384-19.

18. Newman H, Maritz J. Basic overview of method validation in the clinical virology laboratory. Rev Med Virol. 2017;27:e1940.

19. Marcon CE, Campos KR, da Silva GB, Schuelter-Trevisol F, Schlindwein AD, Trevisol DJ, et al. The first survey of human T-cell lymphotropic viruses (HTLV) in HIV/AIDS patients in Santa Catarina State, Brazil. Rev Inst Med Trop Sao Paulo. 2019;61:e53.

20. Caterino-de-Araujo A, Campos KR, Petrucci TV, Silva RX, Lemos MF, Moreira RC. Surveillance of human retroviruses in blood samples from patients with hepatitis B and C in São Paulo, Brazil. Rev Soc Bras Med Trop. 2020;53:e20190378.

21. Rosadas C, Malik B, Taylor GP, Puccioni-Sohler M. Estimation of HTLV-1 vertical transmission cases in Brazil per annum. PLoS Negl Trop Dis. 2018;12:e0006913.

22. Rosadas C, Puccioni-Sohler M, Oliveira AC, Casseb J, Sousa M, Taylor GP. Adult T-cell leukaemia/lymphoma in Brazil: a rare disease or rarely diagnosed? Br J Haematol, 2020;188:e46-9.

23. Haziot ME, Gascon MR, Assone T, Fonseca LA, Luiz OC, Smid J, et al. Detection of clinical and neurological signs in apparently asymptomatic HTLV-1 infected carriers: association with high proviral load. PLoS Negl Trop Dis. 2019;13:e0006967.

24. Araujo AQ, Wedemann D. HTLV-1 associated neurological complex. What is hidden below the water? AIDS Rev. 2019;21:211-7.

25. Campos KR, Gonçalves MG, Costa NA, Caterino-de-Araujo A. Comparative performances of serologic and molecular assays for detecting human $\mathrm{T}$ lymphotropic virus type 1 and type 2 (HTLV-1 and HTLV-2) in patients infected with human immunodeficiency virus type 1 (HIV-1). Braz J Infect Dis. 2017;21:297-305.

26. Silva Brito VS, Santos FL, Gonçalves NL, Araujo TH, Nascimento DS, Pereira FM, et al. Performance of commercially available serological screening tests for human T-cell lymphotropic virus infection in Brazil. J Clin Microbiol. 2018;56:e00961-18.

27. Rosadas C, Tosswill JH, Tedder R, Taylor GP. Pregnancy does not adversely impact diagnostic tests for HTLV-1/2 infection. PLoS Negl Trop Dis. 2019;13:e0007736.

28. Davison KL, Dow B, Barbara JA, Hewitt PE, Eglin R. The introduction of anti-HTLV testing of blood donations and the risk of transfusion-transmitted HTLV, UK: 2002-2006. Transfus Med. 2009;19:24-34.

29. Malik B, Taylor GP. Can we reduce the incidence of adult T-cell leukaemia/lymphoma? Cost-effectiveness of human T-lymphotropic virus type 1 (HTLV-1) antenatal screening in the United Kingdom. Br J Haematol. 2019;184:1040-3. 